\title{
ЛИНГВИСТИКА
}

\section{КОГНИТИВНАЯ ЛИНГВИСТИКА}

DOI $10.37386 / 2305-4077-2021-2-170-187$

\author{
Л. А. Козлова ${ }^{1}$ \\ Алтайский государственный педагогический университет
}

\author{
М. М. Шляхова²
}

Алтайский государственный педагогический университет

\section{ОБРАЗНОЕ СРАВНЕНИЕ КАК ОДНО ИЗ СРЕДСТВ РЕПРЕЗЕНТАЦИИ АВТОРСКОЙ КАРТИНЫ МИРА (НА МАТЕРИАЛЕ ХУДОЖЕСТВЕННЫХ ТЕКСТОВ М. ЭТВУД)}

Объектом исследования статьи является образное сравнение, а предметом - его роль в репрезентации авторской картины мира. Материалом исследования послужили примеры из текстов романов и рассказов М. Этвуд, в которых образное сравнение является одной из характерных черт идиостиля автора, что позволяет предположить, что анализ образных сравнений может служить одним из способов реконструкции авторской картины мира. Как показал комплексный анализ образных сравнений, они служат одним из значимых способов репрезентации доминантных смыслов концептуальной системы автора. Совокупность этих смыслов формирует основу авторской картины мира, которая носит гетерогенный характер, сочетая в себе универсальный, национальный и индивидуальный компоненты, служащие сферой-источником образных сравнений.

Ключевые слова: концептуальная, языковая и авторская картины мира; образное сравнение; художественное мышление; сфера-источник.

\section{A. Kozlova \\ Altai State Pedagogical University \\ M. M. Shlyakhova \\ Altai State Pedagogical University \\ SIMILE AS A MEANS OF THE AUTHOR'S WORLDVIEW MANIFESTATION}

The object of the article is simile, and the subject matter is its role in the representation of the author's worldview. The empirical material is represented by a corpus of examples, found in the works of Margaret Atwood, in which simile appears to be one of the main means of the author's individual style and, consequently, a key to the reconstruction of the author's world view. The complex analysis of the corpus enables us to illustrate the role of simile in the representation

1 Любовь Александровна Козлова, доктор филологических наук, профессор, профессор кафедры английской филологии Алтайского государственного педагогического университета.

2 Марина Михайловна Шляхова, кандидат филологических наук, доцент кафедры английской филологии Алтайского государственного педагогического университета. 
of the author's conceptual system. The totality of these concepts forms the basis of the author's worldview, that has a heterogeneous character, combining the universal, culture-specific and individual components which serve as the source sphere of similes.

Keywords: conceptual, language and author's world view; simile; artistic thinking; source sphere

Развитие когнитивной лингвистики как науки изначально интегративной, направленной, в силу ее антропоцентрической направленности, на сотрудничество со всеми областями знания, объектом которых является человек, способствовало введению таких понятий, как концептуальная картина мира, национальная, языковая, индивидуальная, авторская картина мира, которые появились в результате исследования таких вопросов, как соотношение языка и сознания, языка и культуры, типы мышления, характер знания и средства его репрезентации в языке и т.д. Концептуальная картина мира (ККМ) понимается сегодня как образ мира в нашем сознании, а языковая картина мира (ЯКМ) - как образ мира, репрезентированный в языке.

При рассмотрении вопроса о картине мира одни исследователи предлагают выделять в качестве отдельных объектов рассмотрения концептуальную, научную, художественную, обыденную, языковую, национальную, индивидуальную и т.д. картины мира, другие - выделяют концептуальную и языковую картину мира, при этом рассматривая их как гетерогенные образования, включающие все перечисленные выше составляющие. Мы разделяем вторую точку зрения на том основании, что, если понимать ККМ и ЯКМ не как объективные реалии, а как исследовательские модели, умозрительные построения, используемые для решения каких-либо теоретических или практических задач [Корнилов, 2003, с. 3], то отсутствие единства мнений по данному вопросу следует считать вполне естественным, поскольку они отражают позицию исследователя. Следствием когнитивного подхода к исследованию текста стало введение в метаязык лингвистики понятия авторской, или художественной картины мира, которая трактуется как образ мира, существующий в индивидуальном сознании писателя и находящий свое художественное воплощение в его творчестве [Поцепня, 1997; Кочнова, 2015 и др.]. Исходя из того, что авторская картина мира представляет собой образ мира, «явленный в слове писателя», основным способом реконструкции авторской картины мира считается концептуальный анализ текстов, направленный на выявление и анализ языковых средств репрезентации базовых концептов, совокупность которых формирует авторскую картину мира автора [Бабенко, Казарин, 2005, с. 341].

Объектом настоящей статьи является образное сравнение, а предметом исследования - его роль в репрезентации авторской картины мира. Исследование проводится на материале творчества М. Этвуд, в художественных текстах которой сравнение является одним из основных стилистических приемов, несущих большую смысловую нагрузку. Маргарет Этвуд, художественные тексты которой послужили материалом нашей работы, является автором более чем 40 книг, включающих романы, рассказы для детей, поэтические сборники и сборники эссе. Ее произведения переведены более чем на 40 языков мира, и анализу ее творчества посвящены многочисленные работы лингвистов и литературоведов. Литературоведы и критики отмечают чрезвычайно широкий диапазон проблем, 
которые затрагиваются в ее работах, включая такие вечные темы, как жизнь, смерть, любовь, власть, насилие, экология, место женщины в современном мире [Жаркова, 2017; Cooke, 2004; Grace, 1980; Tolan, 2007 и др.], а лингвисты исследуют жанровое разнообразие ее романов, особенности ее идиостиля, специфику репрезентации базовых концептов в ее романах [Можаева, 2006; Молчанова, 2018; Федосова, 2014 и др.]. При этом отдельных работ, рассматривающих роль образного сравнения в манифестации авторской картины мира М. Этвуд, насколько нам известно, не было выполнено.

Исходя из положения о том, что частотность использования того или иного приема свидетельствует о его значимости в передаче доминантных смыслов текста, мы ставим своей задачей показать роль образного сравнения в репрезентации авторской картины мира. Эмпирический материал исследования составляет около 400 примеров, отобранных методом сплошной выборки из 9 книг М. Этвуд общим объемом 3174 страницы. Основными методами исследования являются концептуальный анализ, направленный на реконструкцию концептов, служащих сферой-источником сравнений, а также лингвостилистический и контекстуальный анализ, используемые при интерпретации смысла и экспрессивного потенциала образных сравнений. Напомним, что понятия сферы-источника и сферы-цели, широко используемые сегодня в работах по метафоре и сравнению, были впервые введены в работе Дж. Лакоффа и М. Джонсона «Метафоры, которыми мы живем», которая сегодня по праву считается «библией когнитивного подхода к метафоре» [Лакофф, Джонсон, 2004].

Сравнение является одной из основных ментальных операций, на которую мы опираемся при освоении как внешнего, так и внутреннего мира. Мы познаем сущность нового, только опираясь на предшествующий опыт и сравнивая новое с тем, что уже известно нам. Как отмечал А. А. Потебня, «самый процесс познания есть процесс сравнения» [Потебня, 1990, с. 114]. В результате сравнения мы выявляем как общность, так и различие между сопоставляемыми сущностями, что позволяет сделать вывод о том, что операции сравнения и дифференциации всегда тесно взаимосвязаны, поскольку дифференциация является следствием операции сравнения. А поскольку на основе дифференциации между сравниваемыми сущностями мы относим их к тому или иному разряду или классу, мы можем заключить, что посредством сравнения мы осуществляем концептуализацию и категоризацию мира. Вербализуя результаты этих процессов с помощью языка, мы используем различные языковые средства, в чем находит свое выражение интерпретирующая функция языка, которая тесно связана с процессами концептуализации и категоризации, поскольку мы познаем мир, одновременно интерпретируя сущность познаваемых нами явлений [Болдырев, 2011]. По мнению А. Ф. Лосева, именно в интерпретирующей функции языка заключается вся сила семантики. Он писал: «Каждый языковой знак есть акт интерпретации как соответствующих моментов мышления, так и соответствующих моментов действительности» [Лосев, 1982, с. 96]. Это объясняет то внимание, которое уделяется категории сравнения в лингвистике, начиная со времен Аристотеля до наших дней и закрепления результатов этого познания в культуре 
Как показывает анализ многочисленных работ по сравнению, выполненных в разное время в контексте разных парадигм, приоритеты в исследовании этого феномена находились и находятся в полном соответствии со сменой научных парадигм лингвистической науки. В традиционной, доструктурной лингвистике сравнение изучалось прежде всего в тесной связи с логическими формами познания, находящими свою репрезентацию в грамматических формах языка, а потому основное внимание уделялось грамматическим средствам его выражения, таким, как степени сравнения и синтаксические компаративные конструкции [Александрова, 1981; Черемисина, 2006 (1971) и др.]. В рамках структурной лингвистики, рассматривающей язык прежде всего как иерархически организованную систему единиц, была значительно расширена область исследования средств выражения сравнения, а сами средства были систематизированы по принципу их уровневой принадлежности [Николаева, URL: http:/www.rspu.edu.ru; Трегубчак, 2008 и дp.]. Функциональная лингвистика, которая сформировалась на основе теории понятийных категорий, сгруппировала многочисленные средства выражения сравнения на основе их смысловой общности в функционально-семантическое поле с разграничением ядерных и периферийных компонентов, выделяемых с учетом «чистоты» выражения ими смысла и частотности их использования для выражения того смысла, вокруг которого они сгруппированы [Левит, 2005; Постникова, 2009 и др.]. С позиций лингвокультурологического подхода, активно развивающегося сегодня, в центре внимания исследователей находится национально-культурная специфика образов сознания, служащих источниками сравнений. Как отмечает В.А. Маслова, в семантике сравнения находит свое отражение специфическое национальное видение мира, поэтому сравнение может выступать как способ познания мира [Маслова, 2001, с. 146-147].

Изучение образного сравнения с позиций когнитивного подхода направлено на реконструкцию тех когнитивных процессов, которые лежат в основе употребления как конвенциональных, стертых сравнений, так и в основе порождения индивидуальных, авторских сравнений. Наибольший интерес, по нашему мнению, сегодня представляют работы, в которых показывается преемственность в развитии лингвистической науки, а именно возможность и целесообразность изучения традиционных стилистических приемов в когнитивном ракурсе, как это показывает в своей работе Е.Г. Беляевская, органически соединяя при этом идеи стилистики декодирования с понятиями когнитивной стилистики и современной теории дискурса [Беляевская, 2013 ].

В когнитивно-ориентированных работах, посвященных образному сравнению, были сделаны попытки описать когнитивные механизмы, лежащие в его глубинной основе. Так, В. Б. Гольдберг рассматривает образность как способ концептуализации, основанный на восприятии признаков объекта, при котором ведущим является зрительное восприятие [Гольдберг, 2013, с.64]. В целом разделяя данную точку зрения, мы хотели бы вместе с тем подчеркнуть, что образ сознания, выступающий в качестве базы-источника, или т.н. когнитивной опоры 
сравнения [Гольдберг, 2011] как особый формат знания, хранящийся в нашем сознании в виде ментальной картинки (mental image), может быть результатом не только непосредственного зрительного восприятия, но и создаваться на основе словесного описания и воображения. Именно на способности нашего сознания в союзе с воображением «рисовать картинку», т.е. создавать зрительный образ, основано задание, часто используемое в работе с детьми и направленное на развитие творческого воображения - нарисовать то, о чем они прочитали или услышали. Такие зрительные образы могут храниться в сознании и участвовать в процессах мышления, которое осуществляется не с опорой на слово, а с опорой на образ, что позволяет говорить о т.н. визуальном мышлении, которое участвует в мыслительной деятельности человека наряду с вербальным мышлением. Мы полагаем, что именно этот тип мышления лежит в основе художественного мышления, отличающегося от обыденного мышления (о художественном мышлении см.: [Жинкин, 1998, с.159]).

Отметим, что во многих исследованиях авторы последовательно разграничивают два типа сравнения: логическое и образное, усматривая это различие в том, что в основании логического сравнения лежит объективное сходство или различие сопоставляемых сущностей, а в основе второго - субъективные ассоциации [Русская грамматика: Академия наук CCCP, URL http:/edu.shd.ru; Малых, 2011, с. 107], т.е. образы сознания, основанные на индивидуальном опыте мировосприятия, в результате чего происходит уподобление одних сущностей другим, на первый взгляд, не имеющим объективного сходства. Проиллюстрируем различие между этими типами сравнений на примере из текста романа М. Этвуд, в котором они употреблены в рамках одного фрагмента текста.

(1) I planned my death carefully; unlike my life, which meandered along from one thing to another, despite my feeble attempts to control it. My life had a tendency to spread, to get flabby, to scroll and festoon like the frame of a baroque mirror, which came from following the line of least resistance (M. Atwood. Lady Oracle).

В приведенном примере употребляются оба типа сравнений. Первое имеет, на наш взгляд, логический характер: сопоставляются две сущности, тесно связанные между собой в нашем сознании - жизнь и смерть. Героиня романа сообщает о том, что она планирует свою смерть (в данном случае, мнимую, собираясь затеряться в другой стране) очень тщательно, в отличие от жизни, для описания которой она использует образное сравнение like the frame of a baroque mirror, в основе которого лежит индивидуальная ассоциативная связь, возникшая в сознании героини, между причудливыми поворотами ее жизни и рамой зеркала, выполненной в стиле барокко. Формальным маркером различий между этими типами сравнений является, на наш взгляд, возможность употребления отрицания в случае логического сравнения, что указывает на различие между сущностями, выявленное в результате сравнения, и невозможность употребления отрицания в случае образного сравнения, поскольку целью образного сравнения является не установление сходства или различия, а уподобление одной сущности другой для ее более полного представления. Можно полагать, что в основе этих сравнений лежит различие между двумя типами мышления: логическим и творческим, 
или образным мышлением, при работе которого, как отмечал Н. И. Жинкин, «задаются новые, так сказать, более «свободные» правила отождествления, логика ограничивается, выражаемое определяется неповторимостью ситуаций и индивидуальностью интонаций» [Жинкин, 1998, с. 162]. Различия же между этими типами мышления обусловлены полушарными различиями. Как отмечают исследователи, хотя процессы речепроизводства связаны в основном с работой левого полушария, правое полушарие не является «языковым идиотом» (is not a linguistic idiot), а, напротив, оно участвует в создании ассоциативных связей, возникновении метафор и коннотаций, интерпретации поэзии, то есть связано непосредственно с языкотворческими процессами [Campbell, 1982, p. 238-353]. Это различие позволяет также предположить, что логическое сравнение выполняет важную роль в процессах концептуализации и категоризации, а образное оказывается более значимым в процессах интерпретации мира с помощью языка, которая всегда носит личностный, субъективный характер. Как подчеркивает Н. Н. Болдырев, интерпретация, понимаемая в узком смысле, «это языковая познавательная деятельность преимущественно отдельного индивида, раскрывающая в своих результатах его субъективное понимание объекта интерпретации» [Болдырев, 2016, с. 179].

С учетом сказанного, представляется актуальным рассмотрение индивидуальных, авторских образных сравнений в когнитивном ракурсе, что позволяет реконструировать специфику работы художественного, творческого мышления, которое всегда индивидуально и лежит в основе формирования особенностей авторского идиостиля и позволяет реконструировать авторскую картину мира, что и является целью нашей работы.

Как было отмечено выше, образное сравнение является одним из основных стилистических приемов, используемых М. Этвуд в своих произведениях. При этом автор варьирует языковые способы его репрезентации. Наряду с прототипическим средством - конструкциями с союзами like и as if, автор широко применяет многочисленные другие средства, которые не содержат формальных маркеров сравнения, но значение сравнения эксплицируется в процессе семантической интерпретации их смысла. Обратимся к примерам: Lady Oracle).

(2) ...I saw that I'd cropped my head like a concentration camp inmate's (M. Atwood.

(3) She drove us briskly along the curriculum as if herding sheep (M. Atwood. Moral Disorder).

(4) The soaker looked like a pair of shorts with pumpkin-shaped legs... (M. Atwood. Moral Disorder).

(5) She was tiny, with blond braids and big blue eyes, and a rabbity way of nibbling on her lower lip as if to keep it from trembling ... (M. Atwood. Moral Disorder).

(6) She accepts him with that dying swan look of hers, the look he can't stand and can't resist (M. Atwood. Life before Man).

(7) Here, a stringy-haired intellectual, pasty-faced, humourless, and morbid; there, a selfsatisfied matron, shut up in a cage of a house that would not be recognized as a cage until it was too late... (M. Atwood. Moral Disorder).

(8) And so I was handed over to Odysseus like a package of meat. A package of meat in a wrapping of gold, mind you. A sort of gilded blood pudding (M. Atwood. The Penelopiad). 
В примерах 2 и 3 сравнение выражено эксплицитно с помощью союзов like и as if; в примерах 4-6 значение сравнения представлено различными способами: с помощью сложного прилагательного pumpkin-shaped, построенного по модели $N+N+e d$, с помощью метафорических эпитетов a rabbit way, that dying swan looks of hers (примеры 5, 6), с помощью биноминальной метафорической структуры a cage of a house, построенной по модели $N$ of $N$ (пример 7). Значение сравнения, содержащееся в их семантике, легко эксплицируется путем перефразирования их смысла: legs shaped like a pumpkin; she nibbled on her lower lip like a rabbit; she looked like a dying swan; the house looked like (resembled) a cage. Пример 8 привлекает к себе внимание тем, что сравнение выражено не одним, а несколькими предложениями, т.е., подобно метафоре, оно становится развернутым. Примечательно также и то, что в процессе своего развертывания сравнение трансформируется в метафору (A sort of gilded blood pudding), что указывает на близость этих приемов в нашем языковом сознании, поскольку в их основе лежит единый когнитивный механизм.

Однако главной особенностью использования образных сравнений является не столько множественность языковых средств, используемых автором, сколько необычайно широкая и разнообразная палитра тех образов, которые служат сферой-источником сравнений в произведениях М. Этвуд. В полном соответствии с тезисом когнитивной лингвистики о том, что концептуальная система человека включает в себя универсальные, национально-специфичные и индивидуальные компоненты, образы сознания, служащие базой-источником сравнений в текстах М. Этвуд, также можно условно разделить на универсальные, национальноспецифические и индивидуальные, признавая при этом значительную диффузность границ между ними. Приведем примеры:

(9) All the little pretend books on the shelves were blank. I asked why there was nothing inside them-I had a dim feeling that there were supposed to be marks on those pages - and my mother said that books were decorations, like vases of flowers (M. Atwood. The Testaments).

В примере 9, взятом из антиутопии «Заветы» (The Testaments), вышедшей в 2019 году, автор описывает атмосферу тоталитарного государства Гилиад, в котором читатель без труда увидит параллели с тем, что сегодня происходит в мире и получило название cancel culture. На полках в доме стоят книги, страницы которых пусты (pretend books), и эти книги, подобно вазам с цветами, служат лишь украшением комнаты. Это простое на первый взгляд образное сравнение, в основе которого лежит понятный представителю любой культуры образ сознания, входящий в ментальную область предметы украшения, несет, на наш взгляд, глубокий смысл: современная массовая литература, лишенная глубокого смысла, всё больше напоминает книгу с пустыми страницами, которая, подобно вазе с цветами, выполняет чисто декоративную, развлекательную функцию.

(10) Specifically, I asked novelists, and I asked them what it felt like when they went into a novel. None of them wanted to know what I meant by into. One said it was like walking into a labyrinth, without knowing what monster might be inside; another said it was like groping through a tunnel; another said it was like being in a cave-she should see daylight through the opening, but she herself was in darkness. Another said it was like being under water, in a lake 
or ocean. Another said it was like being in a completely dark room, feeling her way: she had to rearrange the furniture in the dark, and then when it was all arranged the light would come on. Another said it was like wading through a deep river, at dawn or twilight; another said it was like being in an empty room which was nevertheless filled with unspoken words, with a sort of whispering; another said it was like grippling with an unseen being or entity; another said it was like sitting in an empty theatre before any play or film had started, waiting for the characters to appear (M Atwood. Negotiating with the Dead).

Значительный интерес представляет пример 10, в котором в котором М. Этвуд приводит ответы (возможно, воображаемые) писателей разных стран на ее вопрос о том, с чем можно сравнить процесс создания романа (going into a novel). Несмотря на большое разнообразие образов, лежащих в основе сравнений, они представляют собой своеобразный смысловой повтор, образуя единый образ погружения в темное или пустое пространство, в пещеру или под воду, в лабиринт или туннель, в котором приходится блуждать, с трудом находя путь, а также нахождения в пустом театральном зале в ожидании актеров. Так, на наш взгляд, автор с помощью цепочки сравнений описывает процесс создания книги, который требует погружения автора в глубины подсознания, а также мучительный процесс воплощения мысли в слове (пустая комната - это страница рукописи с еще не написанными словами). Процесс создания книги, по мысли автора, носит универсальный характер, и для метафорического представления этого процесса Этвуд использует универсальные образы сознания, что приводит к установлению иконических отношений между авторским смыслом и формой его воплощения в тексте. Используя универсальные образы, автор тем самым словно подчеркивает наличие общности в картинах мира представителей разных культур, а также наличие в сегодняшнем мироустройстве общих проблем, которые необходимо решать совместными усилиями.

В широкой палитре тем, затрагиваемых в творчестве М. Этвуд, центральное место, по мнению исследователей, занимают вопросы, которые можно объединить термином выживание (survival) [Rubenstein, 1988, p.101]. Это широкое понятие включает в себя такие вопросы, как сохранение природы, сохранение национальной идентичности и национальной культуры, место женщины в современном мире. При этом, будучи канадской женщиной, Этвуд говорит прежде всего о канадской идентичности и канадской женщине. Эти вопросы представлены в концентрированной форме в ее автобиографическом эссе с красноречивым названием "Great Unexpectations”, в котором она в присущей ей иронической манере рассказывает о своем пути в литературу. "I wanted to be-no, worse-was determined to be, was convinced I was-a writer. I was scared to death. I was scared to death for a couple of reasons. For one thing, I was Canadian, and the prospects for being a Canadian and a writer, both at the same time, in I960, were dim. The only writers I had encountered in high school had been dead and English, and in university we barely studied American writers, much less Canadian ones. Canadian writers, it was assumed - by my professors, my contemporaries, and myself-were a freak of nature, like duck-billed platypuses. Logically they ought not to exist, and when they did so anyway, they were just pathetic imitations of the real thing. $\langle\ldots\rangle$ But it was more complicated than that, because, in addition to being a Canadian, I was also a woman" [Atwood, 1988]. 
Канада 40-50 годов прошлого века представляла собой, по словам М. Этвуд, тихую культурную заводь (cultural backwater). Как она позднее напишет об этом в своей работе “Negotiating with the Dead", в то время на полках в большинстве домов канадцев можно было увидеть всего три книги: Библию, Шекспира и книгу Ф.С. Фицджеральда об Омаре Хайяме, а об отношении жителей ее страны к чтению красноречиво говорит заголовок одной из журнальных статей: “Canadians Can Read, But Do They?” (Канадиь умеют читать, но читают ли они?) (M. Atwood. Negotiating with the Dead). А потому перспективы стать писателем, а особенно для женщины, были весьма туманными и не очень привлекательными. Позднее, уже после публикации нескольких романов, отвечая на вопрос о том, почему ее не выдвигают на соискание Нобелевской премии в области литературы, Этвуд назвала две причины: во-первых, потому что она канадка и, во-вторых, потому что она женщина. Сегодня, когда Этвуд выступает во многих университетах мира с лекциями по литературе и получает многочисленные награды за свои книги, мы можем сказать, что своим творчеством она разрушила эти стереотипы. Своими книгами она, с одной стороны, открывает мир для своей страны, а, с другой, открывает свою страну для мира, тем самым способствуя ее превращению из тихой культурной заводи в один из значимых культурных центров. В центре творчества М. Этвуд всегда находилась проблема творческой личности - канадской женщины и теми вызовами, которые ей приходится преодолевать на пути к самоутверждению и успеху (the «paradoxes and dilemmas» of being a Canadian woman artist) [Atwood, 1984].

Анализ образных сравнений, используемых Этвуд, позволяет четко увидеть ее принадлежность к канадской культуре в широком смысле этого понятия. Значительная часть используемых автором образов носит национальноспецифический характер и отражает особенности климата, традиций, растительного и животного мира и быта Канады, хорошо знакомые ей с раннего детства. В своей во многом автобиографической книге "Negotiating with the Dead. A Writer on Writing” [Atwood, 2002] она пишет о том, что, поскольку профессией ее отца было изучение насекомых, каждый год, начиная с шестимесячного возраста, она проводила лето с родителями в лесу на севере Канады, где у отца была небольшая лаборатория, и этот ландшафт стал для нее родным домом. Этот личностный опыт находит свое воплощение в авторских образных сравнениях. Приведем примеры:

(11) Or she'd go into thick, silent rages that were like a dense black fog descending overeveryone (M. Atwood. Moral Disorder).

(12) At the bottom of the stairs there's a hat-and-umbrella stand, the bentwood kind, long rounded rungs of wood curving gently into hooks shaped like the opening fronds of a fern (M. Atwood. The Handmaid's Tale).

(13) By the time she reaches the outer door the humming has just begun again, high pitched, constant, like a mosquito or a child's tuneless song, or a power line in winter (M. Atwood. Life before Man).

(14) I felt as if I was groping through brambles in a night so dark I couldn't see my own hands (M. Atwood. Moral Disorder). 
В примере 11 автор сравнивает атмосферу в доме во время молчаливых приступов ярости своей сестры с плотным черным туманом, который она часто видела нависавшим над лесом: от этих приступов, как от плотного тумана, было невозможно скрыться. Примечательно, что признак плотности, служащий основанием для образного сравнения, находит свое иконическое отражение в употреблении синонимичных прилагательных thick и dense. В примере 11 мы видим, что форма крючков на подставке для шляп и зонтов вызывает у персонажа ассоциацию с распускающимися листьями папоротника. В примере 13 звуки негромкого напевания ассоциируются у персонажа с назойливым гудением комара или электрических проводов зимой. В примере 14 автор говорит о попытках найти контакт со своей сестрой, сравнивая этот процесс с попыткой пробраться в темноте сквозь заросли дикой ежевики. Как видим из приведенных примеров, в основе образных сравнений лежат разные типы модальности восприятия (подробнее об этом см.: [Молчанова, 2018]), что создает у читателя эффект присутствия и позволяет не только увидеть, но и услышать, почувствовать атмосферу канадской провинциальной жизни.

Создавая образ канадской женщины середины прошлого века, автор также использует многочисленные сравнения. При этом обращает на себя внимание тот факт, что образы сознания, служащие основой таких сравнений, не отличаются особой оригинальностью или индивидуальностью: рассказчицы черпают эти образы из «подручного материала»: значительная часть образов, служащих сферой-источником сравнений, отражает привычный и прозаичный быт женщины, предметы, которые ее окружают, ее рутинные занятия. Обратимся к примерам:

(15) It swelled up like a radish (M. Atwood. Bluebeard's Egg and Other Stories).

(16) The blood spurted out like pips from a lemon (M. Atwood. Bluebeard's Egg and Other Stories). Stories).

(17) She has a memory like a rat-trap: full of rats (M. Atwood. Bluebeard's Egg and Other

(18) The hostess had made a whole plateful of decorated cookies for whatever children should be present, and my mother proceeds to describe these: wonderful cookies shaped like bunny rabbits (M. Atwood. Bluebeard's Egg and Other Stories).

Такой нарочито бытовой характер сферы-источника образных сравнений (распухший палец, похожий на редиску; кровь хльлнула, как зернылики из лимона; память, похожая на капкан для крыс; печенья, похожие на кроликов) выполняет, как нам представляется, важную смысловую функцию. Эти сравнения несут на себе печать той эпохи, когда Канада, по словам самой Этвуд, представляла собой «тихую культурную заводь», и мир многих женщин был действительно ограничен их домом и семейными заботами.

Но в то же время в ее стране уже подрастало новое поколение, которое стремилось расширить горизонты этого мира. Вспоминая свое детство и описывая свое восприятие окружающего ее мира, М. Этвуд использует совершенно иные сравнения. В основе этих сравнений лежат образы сознания, почерпнутые ею из книг, за чтением которых она проводила много времени, поскольку ее мать больше всего ценила в детях тишину, а читающий ребенок всегда ведет себя тихо [Atwood, 2002, p.7]. Благодаря чтению перед ней разворачивалась, словно темное полотно, совершенно другая жизнь: 
(19) But another, more secret life spread out before me, like dark fabric (M. Atwood. Moral Disorder).

Именно из книг она узнала о специфике английской культуры, которая оказала и продолжает оказывать значительное влияние на культуру Канады. Именно эти образы, почерпнутые ею из книг, служат основной сферой-источником таких сравнений. Так, говоря о том, что где-то в укромном уголке в картонной коробочке хранятся ее детские волосы, она пишет, что с годами они будут всё больше и больше напоминать траурные украшения викторианской эпохи.

(20) My own hair reposes in a cardboard box in a steamer trunk in my mother's cellar, where I picture it becoming duller and more brittle with each passing year, and possibly motheaten; by now it will look like the faded wreaths of hair in Victorian funeral jewellery (M. Atwood. Bluebeard's Egg and Other Stories).

В результате чтения ее речь стала настолько отличаться от речи матери, что мать смотрела на нее с опаской, словно на пришельца из будущего (a timetraveller come back from the future). И словно в подтверждение этого, М. Этвуд, уже ретроспективно описывая жизнь того времени, сравнивает ее с японской поэзией хайку, используя образ, который бы наверняка испугал ее мать своим непонятным происхождением.

(21) Life was more joyful and innocent then, and at the same time permeated with guilt and terror, or at least the occasions for them, on the most daily level. It was like the Japanese haiku: rigid in its perimeters, within each an astonishing freedom is possible (M. Atwood. Bluebeard's Egg and Other Stories). Этот образ из будущего, используемый для описания прошлого, абсолютно точно воссоздает картину жизни того времени: в ней было много ограничений и запретов, но внутри этих ограничений была удивительная свобода.

Образные сравнений, отражающие индивидуальный компонент авторской картины мира, играют большую роль в создании образов персонажей романов М. Этвуд, в раскрытии их внутреннего мира. Как мы уже отмечали, в центре интересов М. Этвуд находится судьба современной канадской писательницы, что делает ее романы во многом автобиографическими. Сама М. Этвуд в одном из своих интервью говорит о том, что не следует искать в ее героинях только черты ее собственной жизни. Более логично предположить, что, обладая высоко развитым чувством эмпатии, она настолько точно передает внутренний мир своих героинь, что это создает впечатление личной исповеди. Образные сравнения часто выступают основным средством передачи эмоционального состояния ее героинь в наиболее критические моменты их жизни. Обратимся к началу ее романа “Life before Man”.

(22) I don't know how I should live. I don't know how anyone should live. All I know is how I do live. I live like a peeled snail. And that's no way to make money.

I want that shell back, it took me long enough to make. You've got it with you, wherever you are. You were good at removing. I want a shell like a sequined dress, made of silver nickels and dimes and dollars overlapping like the scale of an armadillo. Armored dildo. Impermeable; like a French raincoat.

I wish I didn't have to think about you. You wanted to impress me; well, I am impressed, I'm disgusted. That was a disgusting thing to do, childish and stupid. A tantrum, smashing a doll, but what you smashed was your own head, your own body. You wanted to make damn good and sure I'd never be able to turn over in bed again without feeling that body beside me, not there but tangible, like a leg that's been cut off. Gone but the place still hurts (M. Atwood. Life before Man). 
Отрывок представляет собой ее обращение к человеку, которого уже нет в живых, но с которым она продолжается мысленно общаться даже после его добровольного ухода из жизни. Пять образных сравнений, используемые автором в коротком отрывке (Живу, словно улитка, с которой сняли раковину; мне нужен панцирь, словно расшитое блестками платье; изготовленное из серебряных монет и долларов и укрывающее меня как чешуя броненосиа; непроницаемый, словно плащ; ощущаю его тело словно это ампутированная нога: ее нет, а это место всё еще болит) образуют прием градации, иконически отражая нарастание ее душевной боли, ее желание спрятаться, подобно улитке, в свою раковину, чтобы никто не увидел ее боли от чувства потери, которую она сравнивает с фантомной болью.

Создавая портрет современной канадской женщины - творческой личности, типичным представителем которой является сама М. Этвуд, активно участвующая в феминистском движении, автор «рисует» иную картину мира, тем самым разрушая сложившиеся стереотипы, что также находит свое отражение в используемых ею образных сравнениях. Образные сравнения М. Этвуд поражают разнообразием и неожиданностью сфер-источников, что, с одной стороны, отражает авторскую картину мира, а с другой, поскольку рассказчиком является не автор, а его персонажи, это позволяет автору представить современную канадскую женщину как нестандартную, творческую личность, обладающую своим особым взглядом на мир, активно отстаивающую свои позиции в обществе и в семье, зачастую совершающую иррациональные поступки, остроумную, ироничную и, таким образом, мало похожую на сложившийся стереотип. Приведем примеры.

(23) And he liked living out of suitcases. It must've made him feel like a political refugee (M. Atwood. Lady Oracle).

(24) Living with Nate has been like living with a huge mirror in which her flaws were magnified and distorted ... She'll be free of that (M. Atwood. Life before Man).

(25) He continued to look at me as though I had betrayed him to the Nazis, but he was going to a good spot and not mention it (M. Atwood. Lady Oracle).

(26) Daniel moves through the day enclosed in a glass bubble, like an astronaut on the moon, like a rare plant in a hothouse (M. Atwood. Bodily Harm).

(27) "Upright!". The man shouts, lifting both arms like an orchestra conductor (M. Atwood. Bodily Harm).

В приведенных примерах представлена широкая палитра образов сознания, которые служат сферой-источником сравнения: человек, не распаковывающий свои чемоданы, чувствует себя политическим беженцем (23); жизнь с мужем представляется героине жизнью с огромным зеркалом, которое увеличивает или искажает ее недостатки (24); на героиню смотрят так, как будто она выдала когото нацистам (25); движение человека уподобляется движению астронавту на Луне, редкому тепличному растению (26); энергичное движение рук ассоциируется с дирижером оркестра (27), что имплицитно указывает на широту кругозора современной женщины и ее способность к образному мышлению. 


\section{Подведем краткий итог изложенного.}

1. Сравнение как одна из основных ментальных операций, выполняющая важную роль в процессах концептуализации, классификации и интерпретации мира, всегда оставалась в центре внимания лингвистики, при этом поворачиваясь к исследователям тем аспектом, который находился в центре внимания доминантной парадигмы.

2. Различие между логическим и образным сравнением состоит в том, что первое выполняет важную роль в процессах концептуализации и категоризации, а второе более значимо для процесса интерпретации мира с помощью языка, которая всегда носит личностный, субъективный характер. Поскольку художественный текст представляет собой результат творческого мышления автора, анализ авторских образных сравнений в когнитивном ракурсе позволяет реконструировать авторскую картину мира.

3. Основной особенностью образных сравнений в текстах М. Этвуд является необычайно широкая и разнообразная палитра тех образов, которые служат сферой-источником используемых ею сравнений. Эти образы сознания можно условно разделить на универсальные, национально-специфические и индивидуальные, признавая при этом значительную диффузность границ между ними. Используя универсальные образы, автор подчеркивает значительную общность в картинах мира представителей разных культур, а также наличие в сегодняшнем мироустройстве проблем, которые необходимо решать совместными усилиями. Значительная часть используемых автором образов носит национально-специфический характер и отражает особенности климата, традиций, растительного и животного мира и быта Канады. $B$ основе образных сравнений лежат разные типы модальности восприятия, что создает у читателя эффект присутствия, позволяя не только увидеть, но и услышать, почувствовать атмосферу канадской жизни.

4. Образные сравнения, отражающие индивидуальный компонент авторской картины мира, вносят большой вклад в создание портретов персонажей, в раскрытие их внутреннего мира и их эмоционального состояния. Анализ образных сравнений, используемых М. Этвуд при описании образа канадской женщины середины прошлого века, показывает, что образы сознания, служащие основой таких сравнений, не отличаются особой оригинальностью или индивидуальностью, что иконически отражает привычный и прозаичный быт женщины, ограниченность ее мира. Создавая портрет современной канадской женщины - творческой личности, типичным представителем которой является сама М. Этвуд, автор «рисует» иную картину мира, тем самым разрушая сложившиеся стереотипы, что также находит свое отражение в широкой палитре образов сознания, служащих сферой-источником сравнений.

Заключая, отметим, что анализ только образных сравнений, представленный нами в статье, не позволяет раскрыть всю полноту авторской картины мира такого сложного и многогранного писателя, каким является М. Этвуд. Но даже частично 
реконструированная картина мира автора, проведенная на основе анализа образных сравнений, позволяет, как нам представляется, увидеть ее гетерогенный характер, обусловленный наличием в ней универсальных, национально-специфичных и индивидуальных компонентов.

\section{СПИСОК ЛИТЕРАТУРЫ}

Александрова, С. В. Структурно-семантическая характеристика сравнительных конструкций: автореф. дис. ... канд. филол. наук / С. В. Александрова.-Москва, 1981.- 15 с.

Бабенко, Л.Г. Лингвистический анализ художественного текста. Теория и практика: учебник. 3-е изд., испр. / Л. Г. Бабенко, Ю. В. Казарин.- Москва: Флинта: Наука, 2005.- 496 с.

Беляевская, Е. Г. Концептуальная метафора как источник стилистических приемов в дискурсе / Е.Г. Беляевская // Вопросы когнитивной лингвистики.2013. - № 3.- C. 41-48.

Болдырев, Н.Н. Интерпретирующая функция языка / Н. Н. Болдырев // Вестник Челябинского государственного университета.- 2011.- № 33 (248). Филология. Искусствоведение.-Вып.60.-С. 11-16.

Болдырев, Н.Н. Когнитивная природа языка. Сборник статей / Н. Н. Болдырев.- Москва; Берлин: Direct Media, 2016.-251 с.

Гольдберг, В.Б. Модель познания, отраженная в образном сравнении / В. Б. Гольдберг // Когнитивные исследования языка.- Вып. 8.- Москва - Тамбов: Издательский дом ТГУ им. Г. Р. Державина, 2011.- С. 52-55.

Гольдберг, В.Б. Образность как способ концептуализации действительности / В. Б. Гольдберг // Вопросы когнитивной лингвистики.-2013.№ 1.- С. 64-74.

Жаркова, Е. П. Антиутопии М. Этвуд «Рассказ служанки» и «Трилогия беззумного Аддама» в контексте традиции и новейших тенденций в развитии жанра. Автореф. дис. ... канд. филол. наук / Е. П. Жаркова.- Воронеж, 2017.- 24 с.

Жинкин, Н. И. Язык-речь-творчество. Избранные труды / Н. И. Жинкин.Москва: Лабиринт, 1998.-368 с.

Корнилов, О. А. Языковые картины мира как производные национальных менталитетов. 2-е изд., испр. и доп. / О. А. Корнилов.-Москва: ЧеРо, 2003.-349 с.

Кочнова, К.А. Языковая картина мира писателя: аспекты и методы исследования / К. А. Кочнова // Вестник ВГУ. Серия: Филология. Журналистика.2015. - № 3.- С. 53-56.

Лакофф, Дж., Джонсон, М. Метафоры, которыми мы живем. Пер. с анг. / Под редакцией и с предисловием А.Н. Баранова / Дж. Лакофф, М. Джонсон.Москва: Едиториал, УРРС, 2004.-256c.

Левит, И.В. Сложные сравнительные синтаксические конструкции как элемент функционально-семантического поля сравнения: дис. ... канд. филол. наук / И. В. Левит.-Санкт-Петербург, 2005.- 166 с. 
Лосев, А.Ф. Знак, символ, миф. Труды по языкознанию / А.Ф. Лосев.Москва: Изд-во Москов. ун-та, 1982.- 479 с.

Малых, Л. М. Статус категории сравнения в современных лингвистических исследованиях / Л. М. Малых // Вестник Удмуртского университета. История и филология.- 2011.- Вып.2.- С. 105-110.

Маслова, В. А. Лингвокультурология. Учеб. пособие для студ. высш. учеб, заведений / В. А. Маслова.- Москва: Издательский центр «Академия», 2001.- 208 с.

Можаева, Т.Г. Языковые средства реализации кинематографичности в художественном тексте (на материале произведений Г. Грина, Э. Хемингуэя, М. Этвуд): Дис. ... канд. филол. наук / Т. Г. Можаева.- Барнаул, 2006.- 164 с.

Молчанова, С. Е. Роль образных сравнений в восприятии романа М. Этвуд «Слепой убийца» / С. Е. Молчанова // Балтийский гуманитарный журнал.- 2018.Т. 7.- № 3 (24).- С. 53-56.

Николаева, А.В. Лексические и словообразовательные средства выражения категории компаративности в современном английском языке (на базе словаря Longman Dictionary of Contemporary English) / А.В. Николаева // Международная педагогическая лексикография в теории и практике обучения в высшей школе: сб. тр. Второй междунар. науч.-практ. конф (25-26 августа 2001 г.).- URL: http:/www.rspu.edu.ru (дата обращения: 10.02.2021)

Постникова, С. В. К вопросу о центре функционально-семантического поля сравнения (на материале немецкого языка) / С.В. Постникова // Вестн. Нижегород. ун-та им. Н. И. Лобачевского.- 2009.- № 5.- С. 272-276.

Потебня, А. А. Теоретическая поэтика / А. А. Потебня.- Москва: Высшая школа, 1990.- 344 с.

Поцепня, Д. М. Образ мира в слове писателя: авторефер. дис... д-ра филол. наук / Д. М. Поцепня.- Санкт-Петербург, 1997.-38c.

Русская Грамматика. Академия наук СССР. Институт русского языка.URL: http:/edu.shd.ru (Дата обращения: 10.022021).

Трегубчак, А. В. Семантика сравнения и способы её выражения: дис. ... канд. филол. наук / А. В. Трегубчак.-Рязань, 2008.- 221 с.

Федосова, Т. В. Актуализация концепта «время» в авторской картине мира Маргарет Этвуд / Т. В. Федосова // Вестник КемГУ.- 2014.- № 1 (57).- Т. 2.C. $173-177$.

Черемисина, М.И. Сравнительные конструкции русского языка / М. И. Черемисина.- Москва: Комкнига, 2006 (1971).- 272 с.

Atwood, M. On Being a 'Woman Writer': Paradoxes and Dilemmas / M. Atwood // Second Words: Selected Critical Prose.- Boston: Beacon, 1984.Pp. 190-204.

Atwood, M. Great Unexpectations / M. Atwood // Van Spanckeren and Castro (ed.) Margaret Atwood. Vision and Form.- Carbondale and Edwardville: Southern Illinois University Press, 1988.- Pp. XIII-XVI. 
Atwood, M. Negotiating with the Dead. A Writer on Writing /M. Atwood.Cambridge: Cambridge University Press, 2002.- 224 p.

Campbell, J. Grammatical Man. Information, Enthropy, Language and Life / J. Campbell.- New York: Simon \&Shuster, 1982.- 319 p.

Cooke, N. Margaret Atwood: A Critical Companion / N. Cooke.- Wesport: Greenwood, 2004.- 192 p.

Grace, Sh. Violent Duality: A Study of Margaret Atwood / Sh. Grace.- Toronto: University of British Columbia, 1980.-320 p.

Rubenstein, R. Nature and Nurture in Dystopia. The Handmaid's Tale / R. Rubenstein // Van Spanckeren and Castro (ed.) Margaret Atwood. Vision and Form.Carbondale and Edwardville: Southern Illinois University Press, 1988.- Pp. 101-113.

Tolan, F. Margaret Atwood: Feminism and Fiction / F. Tolan.- New-York: Rodopi, 2007.- 333 p.

\section{СПИСОК ИСТОЧНИКОВ ЦИТИРУЕМЫХ ПРИМЕРОВ}

Atwood, M. Lady Oracle / M. Atwood.- London: Virago Press, 1982.-345p

Atwood, M. Bluebeard's Egg and Other Stories /M. Atwood.- New York: Fawcett Crest, 1983.- 323 p.

Atwood, M. The Handmaid's Tale / M. Atwood.- Toronto: Seal Books, 1986.$293 \mathrm{p}$.

Atwood, M. Bodily Harm / M. Atwood.- Toronto: Seal Books, 1988.- 302 p.

Atwood, M. Life before Man / M. Atwood.- London: Vintage Books, 1996.$309 \mathrm{p}$.

Atwood, M. Negotiating with the Dead. A Writer on Writing / M. Atwood.Cambridge: Cambridge University Press, 2002.- 224 p.

Atwood, M. Moral Disorder / M. Atwood.- London: Virago Press, 2007.- 260 p.

Atwood, M. The Penelopiad / M. Atwood. London: Canongate Book, 2018.$199 \mathrm{p}$.

Atwood, M. The Testaments / M. Atwood. London: Chatto\&Windus, 2019.$419 \mathrm{p}$.

\section{REFERENCES:}

Aleksandrova, S. V. Strukturno-semanticheskaya kharakteristika sravnitel'ny 'kh konstrukczij. avtoref. dis... kand. filol. nauk / S. V. Aleksandrova.-Moskva, 1981.- 15 s.

Babenko, L. G. Lingvisticheskij analiz khudozhestvennogo teksta. Teoriyaipraktika: uchebnik. 3-e izd., ispr. / L. G. Babenko, Yu. V. Kazarin.- Moskva: Flinta: Nauka, 2005.- $496 \mathrm{~s}$.

Belyaevskaya, E. G. Konczeptual naya metafora kak istochnik stilisticheskikh priemov v diskurse / E. G. Belyaevskaya // Voprosy` kognitivnoj lingvistiki.- 2013.№ 3. - S. 41-48.

Boldy`rev, N. N. Interpretiruyushhaya funkcziya yazy`ka / N. N. Boldy`rev // Vestnik Chelyabinskogo gosudarstvennogo universiteta.- 2011.- № 33 (248). Filologiya. Iskusstvovedenie.- Vy`p.60.-S. 11-16. 
Boldy`rev, N. N. Kognitivnaya priroda yazy'ka. Sbornik statej / N. N. Boldy`rev.Moskva; Berlin: DirectMedia, 2016.-251 s.

Gol'dberg, V.B. Model' poznaniya, otrazhennaya v obraznomsravnenii / V. B. Gol’dberg // Kognitivny`e issledovaniya yazy`ka.- Vy`p. 8.- Moskva; Tambov: Izdatel`skij dom TGU im. G. R. Derzhavina, 2011.-S. 52-55.

Gol'dberg, V. B. Obraznost' kak sposob konczeptualizaczii dejstvitel'nosti / V. B. Gol`dberg // Voprosy` kognitivnoj lingvistiki.-2013.- № 1.-S. 64-74.

Zharkova, E.P. Antiutopii M. E`tvud «Rasskaz sluzhanki» i «Trilogiya bezzumnogo Addama» v kontekste tradiczi i novejshikh tendenczij v razvitii zhanra. Avtoref. dis. ... kand. filol. nauk / E. P. Zharkova.-Voronezh, 2017.-24 s.

Zhinkin, N. I. Yazy`k - rech` - tvorchestvo. Izbranny`etrudy` / N. I. Zhinkin.Moskva: Labirint, 1998.-368 s.

Kornilov, O.A. Yazy`kovy`e kartiny` mira kak proizvodny`e naczional`ny`kh mentalitetov. 2-e izd., ispr. i dop. / O. A. Kornilov.-Moskva.: CheRo, 2003.-349 s.

Kochnova, K.A. Yazy`kovaya kartina mira pisatelya: aspekty` imetody` issledovaniya / K.A. Kochnova // Vestnik VGU. Seriya: Filologiya. Zhurnalistika.2015. - № 3.- S. 53-56.

Levit, I. V. Slozhny`e sravnitel’ny`e sintaksicheskie konstrukczii kak e`lement funkczional'no-semanticheskogo polya sravneniya: dis. ... kand. filol. nauk / I. V. Levit.-Sankt-Peterburg, 2005.- 166 s.

Lakoff, Dzh. Metafory, kotorymi my zhivem. Per. s ang. /Pod redakciej i s predisloviem A. N. Baranova / Dzh. Lakoff, M. Dzhonson.-Moskva: Editorial, URRS, 2004.-256s.

Losev, A. F. Znak, simvol, mif. Trudy` po yazy`koznaniyu / A. F. Losev.Moskva: Izd-vo Moskov. un-ta, 1982.-479 s.

Maly`kh, L. M. Status kategorii sravneniya sovremenny`kh lingvisticheskikh issledovaniyakh / L. M. Maly`kh // Vestnik Udmurtskogo universiteta. Istoriya i filologiya.-2011.-Vy’p.2.-S. 105-110.

Maslova, V.A. Lingvokul`turologiya. Ucheb. posobiedlya stud. vy`ssh. ucheb, zavedenij / V. A. Maslova. - Moskva: Izdatel`skijczentr «Akademiya», 2001.-208 s.

Mozhaeva, T. G. Yazy'kovy`e sredstva realizaczii kinematografichnosti v khudozhestvennom tekste (na material proizvedenij G. Grina, E`. Khemingue'ya, M. E`tvud): Dis. ... kand.. filol. nauk / T. G. Mozhaeva.-Barnaul, 2006.-164 s.

Molchanova, S. E. Rol` obrazny`kh sravnenij v vospriyatii romana M. E`tvud «Slepoj ubijcza» / S. E. Molchanova // Baltijskij gumanitarny`jzhurnal.-2018.- T. 7.№ 3 (24).- S. 53-56.

Nikolaeva, A.V. Leksicheskie i slovoobrazovatel`ny`e sredstva vy`razheniya kategorii komparativnosti $\mathrm{v}$ sovremennom anglijskom yazy'ke (na baze slovarya Longman Dictionary of Contemporary English) / A. V. Nikolaeva // Mezhdunarodnaya pedagogicheskaya leksikografiya $\mathrm{v}$ teorii i praktike obucheniya $\mathrm{v}$ vy`sshej shkole: sb. tr.Vtoroj mezhdunar. nauch.-prakt. konf (25-26 avgusta 2001g.) -URL: http:/ www. rspu.edu.ru (data obrashheniya: 10.02.2021) 
Postnikova S. V. K voprosu o czentre funkczional'no-semanticheskogo polya sravneniya (na material nemeczkogoyazy`ka) / S. V. Postnikova // Vestn. Nizhegorod. un-ta im. N. I. Lobachevskogo.-2009.-№ 5.- S. 272-276.

Potebnya,A.A. Teoreticheskaya poe'tika / A. A. Potebnya.-Moskva: Vy`sshaya shkola, 1990.-344 s.

Poczepnya, D. M. Obraz mira v slove pisatelya: avtorefer. dis. ... d-ra filol. nauk / D. M. Poczepnya.-Sankt-Peterburg, 1997.-38 s.

Russkaya Grammatika. Akademiya nauk SSSR. Institut russkogo yazy`ka.URL: http:/edu.shd.ru (Data obrashheniya: 10.022021).

Tregubchak, A. V. Semantika sravneniya i sposoby` eyo vy`razheniya: dis. ... kand. filol. nauk / A. V. Tregubchak.-Ryazan', 2008.-221 c.

Fedosova, T. V. Aktualizacziya konczepta «vremya» v avtorskoj kartine mira Margaret E`tvud / T. V. Fedosova // VestnikKemGU.- 2014.- № 1 (57).- T. 2.S. 173-177.

Cheremisina, M. I. Sravnitel'ny`e konstrukczii russkogo yazy`ka / M. I. Cheremisina.-Moskva: Komkniga, 2006 (1971).-272 s.

Atwood, M. On Being a 'Woman Writer': Paradoxes and Dilemmas / M. Atwood // Second Words: Selected Critical Prose.- Boston: Beacon, 1984.Pp. 190-204.

Atwood, M. Great Unexpectations / M. Atwood // Van Spanckeren and Castro (ed.) Margaret Atwood. Vision and Form.- Carbondale and Edwardville: Southern Illinois University Press, 1988.-Pp. XIII-XVI.

Atwood, M. Negotiating with the Dead. A Writer on Writing /M. Atwood.Cambridge: Cambridge University Press, 2002.-224 p.

Campbell, J. Grammatical Man. Information, Enthropy, Language and Life / J. Campbell.- New York: Simon \&Shuster, 1982.-319 p.

Cooke, N. Margaret Atwood: A Critical Companion / N. Cooke.- Wesport: Greenwood, 2004.- 192 p.

Grace, Sh. Violent Duality: A Study of Margaret Atwood / Sh. Grace.- Toronto: University of British Columbia, 1980.-320 p.

Rubenstein, R. Nature and Nurture in Dystopia. The Handmaid's Tale / R. Rubenstein // Van Spanckeren and Castro (ed.) Margaret Atwood. Vision and Form.Carbondale and Edwardville: Southern Illinois University Press, 1988.-Pp. 101-113.

Tolan, F. Margaret Atwood: Feminism and Fiction / F. Tolan.- New-York: Rodopi, 2007.- 333 p. 